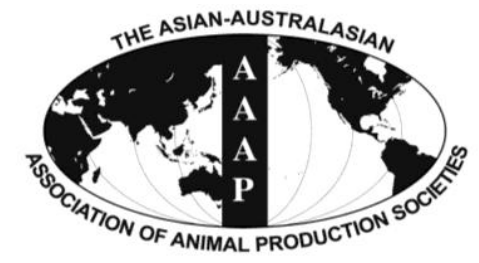

Asian Australas. J. Anim. Sci.

Vol. 26, No. 5 : 732-742 May 2013

http://dx.doi.org/10.5713/ajas.2012.12619

Www.ajas.info

pISSN $1011-2367$ elSSN 1976-5517

\title{
Flavour Chemistry of Chicken Meat: A Review
}

\author{
Dinesh D. Jayasena, Dong Uk Ahn ${ }^{1}$, Ki Chang Nam ${ }^{2}$ and Cheorun Jo* \\ Department of Animal Science and Biotechnology, Chungnam National University, Daejeon 305-764, Korea
}

\begin{abstract}
Flavour comprises mainly of taste and aroma and is involved in consumers' meat-buying behavior and preferences. Chicken meat flavour is supposed to be affected by a number of ante- and post-mortem factors, including breed, diet, post-mortem ageing, method of cooking, etc. Additionally, chicken meat is more susceptible to quality deterioration mainly due to lipid oxidation with resulting off-flavours. Therefore, the intent of this paper is to highlight the mechanisms and chemical compounds responsible for chicken meat flavour and off-flavour development to help producers in producing the most flavourful and consistent product possible. Chicken meat flavour is thermally derived and the Maillard reaction, thermal degradation of lipids, and interaction between these 2 reactions are mainly responsible for the generation of flavour and aroma compounds. The reaction of cysteine and sugar can lead to characteristic meat flavour specially for chicken and pork. Volatile compounds including 2-methyl-3-furanthiol, 2-furfurylthiol, methionol, 2,4,5-trimethyl-thiazole, nonanol, 2-trans-nonenal, and other compounds have been identified as important for the flavour of chicken. However 2-methyl-3-furanthiol is considered as the most vital chemical compound for chicken flavour development. In addition, a large number of heterocyclic compounds are formed when higher temperature and low moisture conditions are used during certain cooking methods of chicken meat such as roasting, grilling, frying or pressure cooking compared to boiled chicken meat. Major volatile compounds responsible for fried chicken are 3,5-dimethyl-1,2,4-trithiolanes, 2,4,6-trimethylperhydro-1,3,5-dithiazines, 3,5diisobutyl-1,2,4-trithiolane, 3-methyl-5-butyl-1,2,4-trithiolane, 3-methyl-5-pentyl-1,2,4-trithiolane, 2,4-decadienal and trans-4,5-epoxytrans-2-decenal. Alkylpyrazines were reported in the flavours of fried chicken and roasted chicken but not in chicken broth. The main reason for flavour deterioration and formation of undesirable "warmed over flavour" in chicken meat products are supposed to be the lack of $\alpha$-tocopherol in chicken meat. (Key Words: Flavour, Chicken Meat, Maillard Reaction, Lipid Oxidation, Heterocyclic Compounds)
\end{abstract}

\section{INTRODUCTION}

Continued consumption of meat and meat products can be ensured through a tasty, nutritious and safety meat supply for the consumers (Joo and Kim, 2011). Appearance, taste, aroma, and texture of meat can generally persuade a consumer's decision to purchase meat. Flavour comprises mainly of taste and aroma and involves in consumers' meatpurchasing behavior and preferences even before the meat is eaten (Shahidi, 1989; Sitz et al., 2005). It is well known that raw meat has only a blood-like taste with little or no aroma. Aromatic notes and most of the characteristic flavours responsible for the development of meat flavour

\footnotetext{
* Corresponding Author: Cheorun Jo. Tel: +82-42-821-5774, Fax: +82-42-825-9754, E-mail: cheorun@cnu.ac.kr

${ }^{1}$ Department of Animal Science, Iowa State University, Ames, IA 50011-3150, USA.

${ }^{2}$ Department of Animal Science and Technology, Sunchon National University, Suncheon, 540-742, Republic of Korea. Submitted Nov. 6, 2012; Accepted Jan. 14, 2013; Revised Jan. 26, 2013
}

are primarily contributed by the volatile compounds originated through heat induced complex reactions between non-volatile components of lean and fatty tissues during cooking (Mottram, 1998).

Chicken, the cheapest commercially produced meat in a global context, is supposed to have an increase in consumption by $34 \%$ by 2018 (Jung et al., 2011). Being a white meat, chicken meat is more superior to red meat due to several other reasons, including its health benefits, as it contains less fat and cholesterol, easy to handle portions and less religious barriers (Liu et al., 2012). Few fast-growing commercial broiler strains play the vital role in producing the required amount of chicken meat to the world population (Jaturasitha et al., 2008). This is further supported by the production of meat from indigenous chicken breeds which have been neglected over the years. However, the meat from indigenous chicken breeds is considered as a delicacy because of its unique taste and texture compare to commercial broilers. As a result the price of the indigenous chicken meat is 2 or 3 times higher 
than that of commercial broilers (Wattanachant et al., 2004; Choe et al., 2010).

Chicken meat flavour, however, relies on several production and processing factors including the breed/strain of chicken, diet of bird, presence of free amino acids and nucleotides, irradiation, high pressure treatment, cooking, antioxidants, $\mathrm{pH}$ and ageing. Therefore these ante- and postmortem factors can influence the status of chicken meat flavour. Additionally, chicken meat is more susceptible for quality deterioration mainly due to lipid oxidation and resulting off-flavours because chicken meat contains higher levels of unsaturated fatty acids compared to red meat. This off-flavour development is supposed to be one of the main problems regarding the quality of the chicken meat. As a result, the producers and processors in chicken meat sector, and even consumers try to avoid off-flavour development through various prevention mechanisms. Understanding the chemistry of chicken meat flavour is therefore vital in order to produce the most flavourful and consistent product possible. The intent of this paper is to highlight different mechanisms and chemical compounds responsible for chicken meat flavour and off-flavour development in detail and to brief the main factors affecting chicken meat flavour.

\section{GENERAL CHEMISTRY OF CHICKEN MEAT FLAVOUR}

Bloody, metallic, and salty taste is generally a unique characteristic of fresh uncooked meat. Its aroma resembles blood serum (Wasserman, 1972; Joo and Kim, 2011). However, significant changes take place in the flavour of meat during cooking. The main reactions involved during cooking that are responsible for flavour developemnt are Maillard reaction, thermal degradation of lipids and Maillard-lipid interactions (Brunton et al., 2002). Flavour gets developed during cooking through complex reactions between components found in raw meat combining with heat. More than 1,000 chemicals have so far been identified in the volatiles of different muscle foods (Shahidi et al., 1994). Majority of the volatile compounds identified in cooked poultry meat, have been recognized in chicken (Brunton et al., 2002). However many of these have little influence on flavour of meat and relatively few make a key contribution to the odour and flavour of cooked meat (Aliani and Farmer, 2005). Melton (1999) has named sweet, sour, salty, bitter and the "umami" or savory taste as the basic tastes of meat. Hydrocarbons, aldehydes, ketones, alcohols, furans, thriphenes, pyrrols, pyridines, pyrazines, oxazols, thiazols, sulfurous compounds (Figure 1), and many others have been identified as the flavour and aroma compounds found in meat (Ho et al., 1994; MacLeod, 1994). Therefore, sulfurous and carbonyl compounds are considered to be the principal contributors to meat flavour

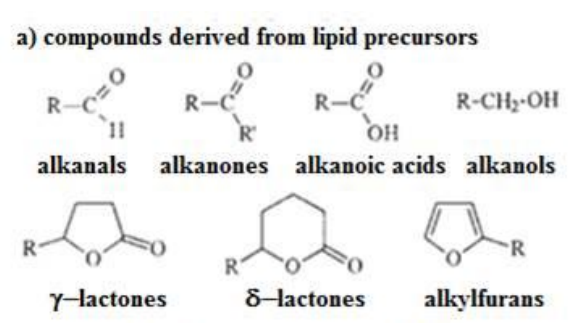

b) compounds derived from water-soluble precursors

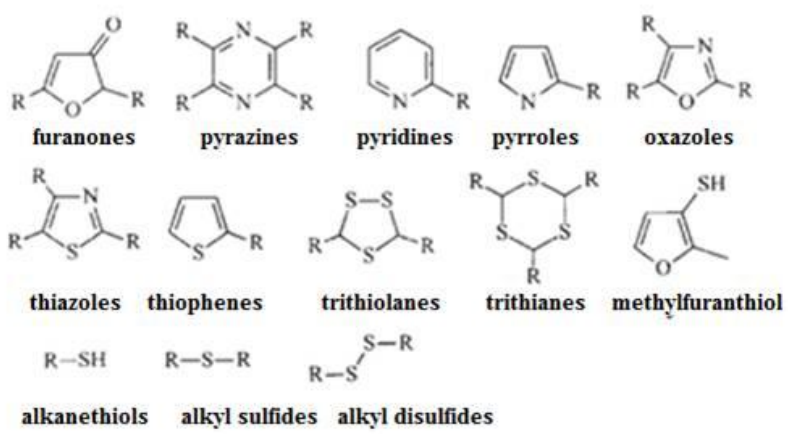

Figure 1. Major classes of volatile compounds produced during the cooking of chicken meat (Mottram, 1998).

(Perez-Alvarez et al., 2010).

With respect to chicken meat, many of their key flavour and odour compounds together with the mechanisms for the formation have been identified (Aliani and Farmer, 2005). According to Shi and Ho (1994), 16 primary odour components have been identified in chicken broth, of which 14 are structurally identified. They further demonstrated that 2-methyl-3-furanthiol, generated from the Maillard reaction and lipid oxidation, as the most vital chemical compound responsible for the meaty flavour of chicken broth. In addition, other volatile compounds originated from above two reactions include 2-furfurylthiol, methionol, 2,4,5-trimethylthiazole, nonanol, 2-trans-nonenal, 2-formyl5-methylthiophene, p-cresol, 2-trans-4-trans-nonadienal, 2-trans-4-trans-decadienal, 2 -undecenal, $\beta$-ionone, $\gamma$ decalactone and $\gamma$-dodecalactone. These compounds are obviously the major sources of chicken flavour (Shi and Ho, 1994; Varavinit et al., 2000). Sasaki et al. (2007) showed that components responsible for umami characteristics contribute to the brothy taste of meat. With respect to the primary odourants of the broth, 2-trans-4-trans-decadienal and $\gamma$-dodecalactone predominated in chicken broth compare to that of beef (Table 1)

\section{Flavour precursors of chicken meat}

The major flavour precursors found in meat including chicken meat can be divided into two main groups: water soluble components and lipids (Mottram, 1998). Although the flavour of meat from different species upon heat processing is expected to be similar due to the similarities of the free amino acids and carbohydrates in their meat 
Table 1. Flavour dilution factors of odourants identified in broths from chicken and beef (adapted from Gasser and Grosch, 1990)

\begin{tabular}{lrrc}
\hline \multirow{2}{*}{ Compounds } & \multicolumn{2}{c}{$\begin{array}{c}\text { Flavour dilution } \\
\text { factor }\end{array}$} & $\begin{array}{c}\text { Odour } \\
\text { description }\end{array}$ \\
\cline { 2 - 3 } & Chicken & Beef & \\
\hline 2-Methyl-3-furanthiol & 1,024 & 512 & Meat-like, sweet \\
bis (2-Methyl-3-furyl) & $<16$ & 2,048 & Meat-like \\
\cline { 2 - 3 } disulphide & & & \\
2-furfurylthiol & 512 & 512 & Roasty \\
2,5-dimethyl-3-furanthiol & 256 & $<16$ & Meaty \\
3-mercapto-2-pentanone & 128 & 32 & Sulphurous \\
Methionol & 128 & 512 & Cooked potato \\
2,4,5-trimethylthiazole & 128 & $<16$ & Earthy \\
2-formyl-5-methylthiophene & 64 & 64 & Sulphurous \\
Phenylacetaldehyde & 16 & 64 & Honey-like \\
2-trans-4-trans-decadienal & 2,048 & $<16$ & Fatty \\
2-trans-4-cis-decadienal & 128 & $<16$ & Fatty, tallowy \\
2-undecenal & 256 & $<16$ & Tallowy, sweet \\
$\gamma$-dodecalactone & 512 & $<16$ & Tallowy, fruity \\
$\gamma$-decalactone & 64 & $<16$ & Peach-like \\
Nonanol & 64 & $<16$ & Tallowy, green \\
2-trans-nonenal & 64 & $<16$ & Tallowy, fatty \\
2-trans-4-trans-nonadienal & 64 & $<16$ & Fatty \\
3-ionone & 64 & $<16$ & Violet-like \\
p-cresol & 64 & $<16$ & Phenolic \\
\hline & & &
\end{tabular}

(Shahidi, 2002), it was challenged by the lipid-derived species-specific notes, mainly from the intramuscular lipids (Perez-Alvarez et al., 2010). In other words, differences in lipid-derived volatile components between species are mainly responsible for the species differences in flavour, whereas the precursors supplied by lean tissues generate the meaty flavour common to all cooked meats (Mottram, 1998).

Mottram (1998) reported free sugars, sugar phosphates, nucleotide bound sugars, free amino acids, peptides, nucleotides and other nitrogenous components, such as thiamine as the main water-soluble flavour precursors. The reaction of cysteine and sugar can lead to characteristic meat flavour specially for chicken and pork (Varavinit et al., 2000). This was further confirmed by a research where the quantities of carbohydrates and amino acids, in particular ribose and cysteine, are reduced during heating. The main carbohydrates with flavour-forming potential include ribose, ribose-5-phosphate, glucose and glucose-6-phosphate (Meinert et al., 2009). Ribose which is associated with the ribonucleotides in the muscle is highly involved in flavour producing reactions during heating of meat (Mottram, 1998).

However, many flavour compounds may be formed by two or more possible mechanisms. The best example is 2methyl-3-furanthiol which is responsible for the meaty flavour of chicken broth (Shi and Ho, 1994; Aliani and Farmer, 2005). Principal precursors for 2-methyl-3- furanthiol are pentose sugars and cysteine/cystine/ glutathione or thiamine. As pentose sugars are mainly derived from ribonucleotides, in particular inosine-5'monophosphate (IMP), 2-methyl-3-furanthiol and its disulfide can be formed from reaction of IMP or ribose with cysteine or cystine or glutathione or by thiamine degradation (Figure 2; Shi and Ho, 1994; Melton, 1999). Therefore, the relative importance of each precursor for flavour generation in cooked chicken meat is still unclear (Aliani and Farmer, 2005).

\section{Lipid derived volatiles in chicken flavour}

The role of lipid-derived carbonyl compounds in poultry flavour has been assessed by many researchers over the years. The lean meat contains intramuscular triglycerides and structural phospholipids. Therefore, desirable as well as undesirable flavours can be resulted in meat due to lipid oxidation. Mild thermal oxidative changes of lipids lead to generation of desirable flavour compounds and aromas in cooked meats (Shahidi, 2002).

Similar to other meats, the flavour development of poultry meat is partly attributed to its lipids (Perez-Alvarez et al., 2010). Several hundred volatile compounds are generated in cooked meat through the lipid degradation, primarily the oxidation of the fatty acid components of lipids. Such compounds includes aliphatic hydrocarbons, aldehydes, alcohols, ketones, esters, carboxylic acids, some aromatic hydrocarbons (Figure 1), and oxygenated heterocyclic compounds such as lactones and alkylfurans (Mottram, 1998). Forty-one out of 193 total compounds reported in the flavour of roasted chicken are lipid-derived aldehydes. Selected aldehydes identified in roasted and cooked chicken flavour are shown in Table 2 (Shi and Ho,

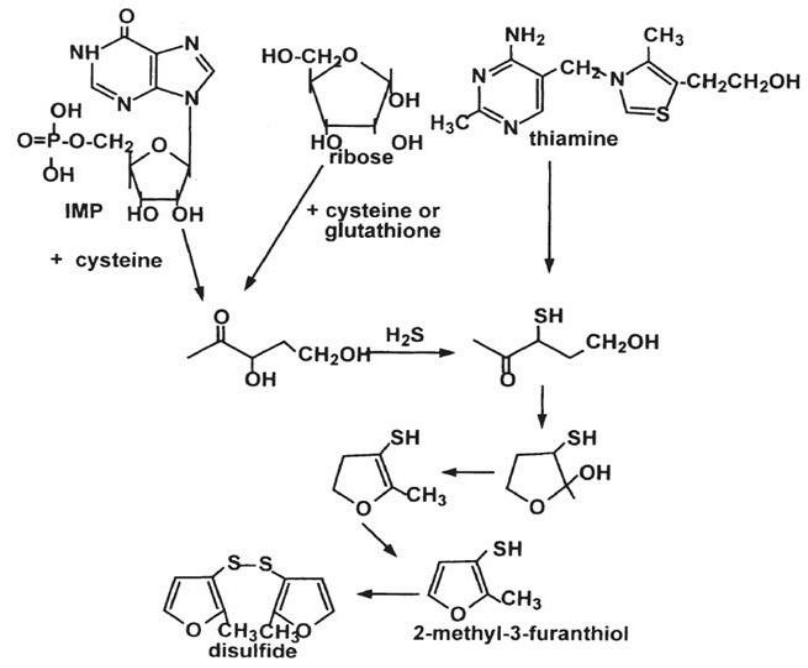

Figure 2. Mechanism for formation of 2-methyl-3-furanthiol and its disulfide by interaction of pentose sugars with cysteine or glutathione or by degradation of thiamine (Melton, 1999). 
1994). According to the Table 2, hexanal and 2,4-decadienal are the most abundant aldehydes identified in chicken flavour which are known to be the primary oxidation products of linoleic acid (Figure 3). However, 2,4decadienal is considered as a more important odourant for chicken flavour compared to hexanal due to its much lower odour threshold (Shi and Ho, 1994).

Several studies have confirmed that phospholipids are much more important in the development of aroma volatiles during the cooking of meat than the triglycerides (Mottram, 1998). This is attributed to the presence of much higher proportion of unsaturated fatty acids, including significant amounts of polyunsaturated fatty acids such as arachidonic

Table 2. Selected aldehydes identified in roasted and cooked chicken flavour (adapted from Shi and Ho, 1994)

\begin{tabular}{|c|c|c|}
\hline \multirow[b]{2}{*}{ Aldehyde } & \multicolumn{2}{|c|}{ Concentration (mg per kg) } \\
\hline & $\begin{array}{l}\text { Roasted } \\
\text { chicken }\end{array}$ & $\begin{array}{c}\text { Cooked chicken } \\
\text { meat }\end{array}$ \\
\hline Butanal & 0.133 & \\
\hline Pentanal & 0.319 & \\
\hline Hexanal & 1.804 & 25.6 \\
\hline Heptanal & 0.212 & 2.1 \\
\hline Octanal & 0.422 & 2.3 \\
\hline Nonanal & 0.467 & 1.7 \\
\hline Decanal & 0.052 & 0.3 \\
\hline Undecanal & 0.058 & \\
\hline Dodecanal & 0.022 & \\
\hline Tridecanal & 0.151 & \\
\hline Tetradecanal & 0.125 & 0.2 \\
\hline Pentadecanal & 0.383 & \\
\hline Hexadecanal & 19.788 & 1.4 \\
\hline Heptadecanal & 0.276 & 0.1 \\
\hline Octadecanal & 2.664 & \\
\hline trans-2-butenal & $\operatorname{tr}$ & \\
\hline cis-2-pentenal & $\operatorname{tr}$ & \\
\hline trans-2-pentenal & 0.085 & 1.1 \\
\hline cis-2-hexenal & $\operatorname{tr}$ & \\
\hline trans-2-hexenal & 0.060 & 0.3 \\
\hline trans-2-heptenal & 0.104 & 1.2 \\
\hline cis-2-octenal & 0.004 & \\
\hline trans-2-octenal & 0.195 & 3.7 \\
\hline trans-2-nonenal & 0.084 & \\
\hline cis-2-decenal & 0.003 & \\
\hline trans-2-decenal & 0.139 & 1.0 \\
\hline cis-2-undecenal & 0.002 & \\
\hline trans-2-undecenal & 0.139 & 0.4 \\
\hline trans-dodecenal & 0.002 & 0.3 \\
\hline trans,cis-2,4-nonadienal & $\operatorname{tr}$ & \\
\hline trans,trans-2,4-nonadienal & $\operatorname{tr}$ & 0.3 \\
\hline trans,cis-2,4-decadienal & 0.051 & 1.0 \\
\hline trans,trans-2,4-decadienal & 0.137 & 5.2 \\
\hline trans,trans-2,4-undecadienal & 0.001 & 0.2 \\
\hline
\end{tabular}

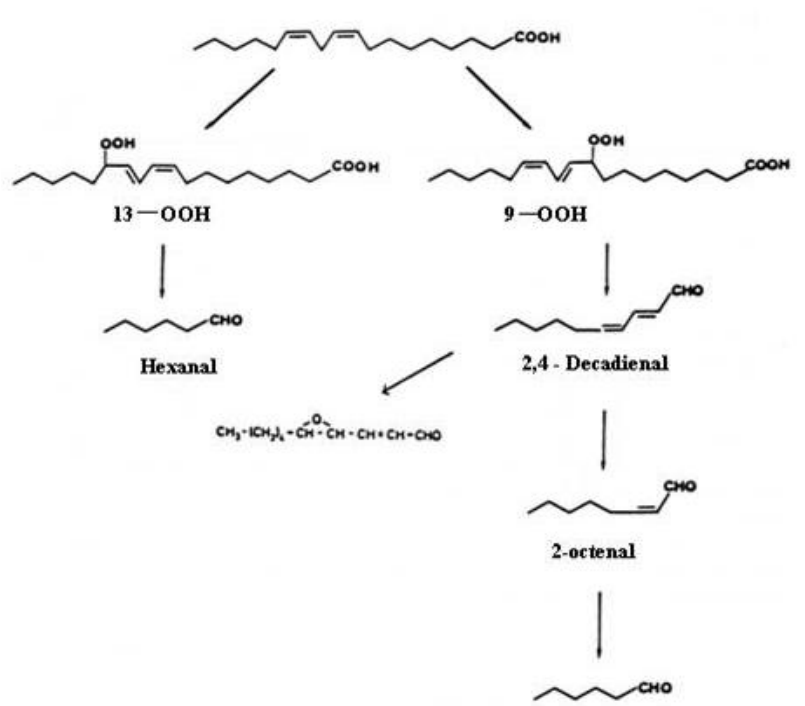

Figure 3. Oxidation and degradation products of linoleic acid (Shi and Ho, 1994).

acid (20:4) in phospholipids (Mottram and Edwards, 1983). Saturated and unsaturated aldehydes having green, fatty and tallowy aroma play a vital role in all cooked meat aroma (Mottram, 1998). The higher levels of unsaturated fatty acids in chicken compared with red meat generate more unsaturated volatile aldehydes which are vital in determination of specific aromas of chicken meat (Noleau and Toulemonde, 1987). Further, the aroma of fat-fried food is reported to be due to 2,4-decadienal (Mottram, 1998). Therefore aliphatic aldehydes contribute to the fatty flavours of cooked meat including chicken meat.

A different composition of volatiles that is responsible for the desirable flavours gets formed due to quick reactions taken place in cooked meat (Mottram, 1998) compare to those volatiles formed during long-term storage leading to rancid off-flavours. In chicken meat, lack of $\alpha$-tocopherol is however considered as the main reason for meat flavour deterioration and formation of undesirable "warmed over flavour (WOF)" in chicken meat products (Shahidi, 2002). Lipid-derived compounds in meat volatiles have greater odour threshold values (Table 3) as opposed to sulfur- and nitrogen-containing heterocyclic compounds which make them less aroma significant. Even at relatively low concentrations, heterocyclic compounds possess a significant effect on aroma due to their low odour threshold values (Mottram, 1998).

\section{Volatiles from the Maillard reaction in chicken flavour}

The Maillard reaction is one of the main chemical reactions that take place during cooking of meat including chicken meat. This typically occurs between amino compounds and reducing sugars and eventually results a large number of compounds responsible for the flavour of 
Table 3. Odour thresholds of some volatiles identified in boiled meat (adapted from Gasser and Grosch, 1990)

\begin{tabular}{lc}
\hline Compound & Threshold (ng/L; air) \\
\hline 2-methyl-3-furanthiol & $0.0025-0.001$ \\
Bis (2-methyl-3-furyl)disulphide & $0.0007-0.0028$ \\
2-furfurylthiol & $0.0045-0.002$ \\
2,5-dimethyl-3-furanthiol & $0.0035-0.014$ \\
3-mercapto-2-pentanone & $0.045-0.18$ \\
2,4,5-trimethylthiazole & $1.8-7.2$ \\
2-formyl-5-methylthiophene & $1.75-7.4$ \\
2,4-decadienal & $0.04-0.16$ \\
\hline
\end{tabular}

any meat (Mottram, 1994a). During the initial stages of this reaction, Amadori products are formed via glycosylamine as a result of condensation of the carbonyl group of a reducing sugar with amino compounds. Various sugar dehydration and degradation products such as furfural and furanone derivatives, hydroxyketones and dicarbonyl compounds are formed by rearranging and dehydration of the resulted product via deoxyosones. Subsequently these compounds interact with other reactive components such as amines, amino acids, aldehydes, hydrogen sulfide, and ammonia and the aroma compounds are formed (Mottram, 1998; Calkins and Hodgen, 2007).

Strecker degradation of amino acids by Maillard reaction-derived dicarbonyl compounds is a vital associated reaction, during which an aldehyde is formed due to the decarboxylation and deamination of an amino acid and an $\alpha$-aminoketone or amino alcohol is resulted from the dicarbonyl compound as well. Hydrogen sulfide, ammonia and acetaldehyde are also formed by Strecker degradation when cysteine is used as the amino acid (Figure 4; Mottram, 1998). Maillard reaction-derived carbonyl compounds act

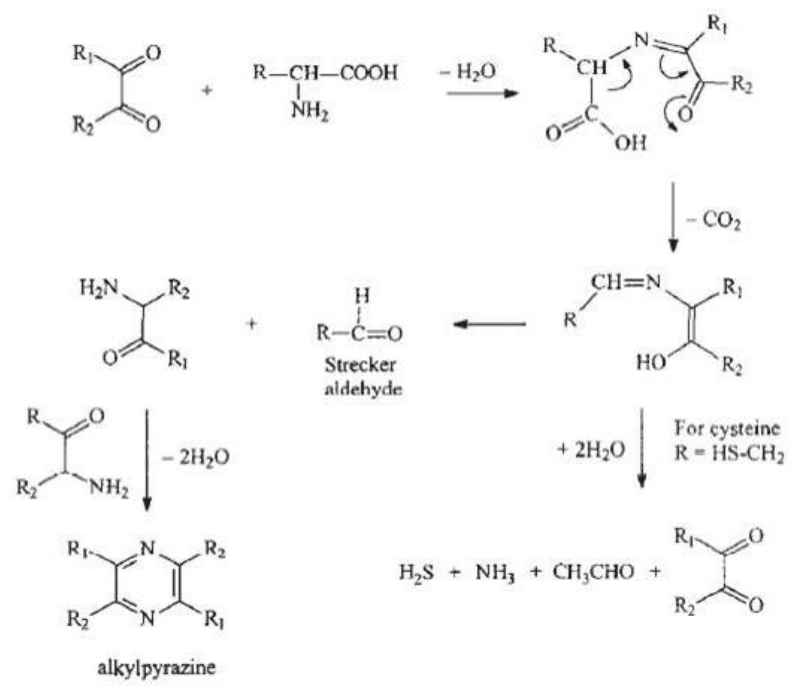

Figure 4. Strecker degradation of amino acids and the formation of hydrogen sulfide, ammonia and acetaldehyde from cysteine (Mottram, 1998). with these compounds forming intermediates that further involve in flavour-forming reactions. This eventually produces many important classes of flavour compounds including furans, pyrazines, pyrroles, oxazoles, thiophenes, thiazoles and other heterocyclic compounds (Figure 5; Melton, 1999). Shahidi (1989) and Mottram and Madruga (1994) reported that sulfur-compounds derived from ribose and cysteine, and carbonyl compounds are the principal contributors to meat flavour. Ribose is considered as the most important flavour precursor in chicken (Meinert et al., 2009). In addition, thiamine has also been proved as an important precursor that provides wide range of sulfur compounds (Aliani and Farmer, 2005). Due to the degradation process of nucleotides such as IMP, ribose is formed and it is then involved in a number of secondary reactions yielding a large number of volatile compounds (Kavitha and Modi, 2007). Hence, IMP is generally considered as the major nucleotide in muscle that imparts flavour to the meat (Yamaguchi, 1991). In general, the IMP content in chicken meat is 75 to $122 \mathrm{mg} / 100 \mathrm{~g}$ (Maga, 1983) but some differences among breeds exist (Jung et al., 2011).

Formation of 2-methyl-3-furanthiol in chicken broth via Maillard reaction involves interaction between ribose and sulphur-containing amino acids (cysteine or cystine) or peptide (glutathione). Glutathione liberates hydrogen sulphide rapidly during the initial stages of cooking whereas cysteine does upon prolonged heating. Another important odourant in chicken broth, 2-furfurylthiol, is formed from the reaction between furfural and cysteine (Shi and Ho, 1994). In addition, the Maillard reaction-derived volatiles are the major components in meat grilled under severe conditions (Mottram, 1998).

\section{Volatiles compounds from lipid-Maillard interactions}

Whitfield (1992) and Mottram (1994b) reported that the interaction of lipid with the Maillard reaction leads to formation of a number of volatiles that have been identified in meat (Figure 6). Volatile compounds originating from

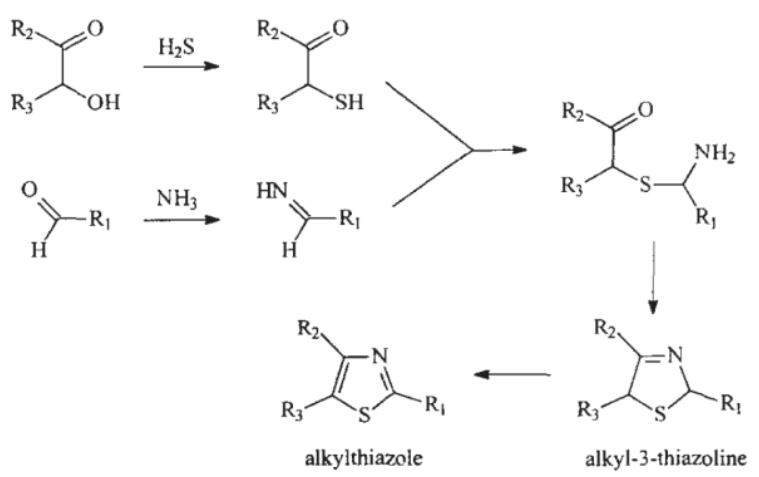

Figure 5. Mechanism for the formation of thiazolines and thiazoles in the Maillard reaction (Mottram, 1998). 


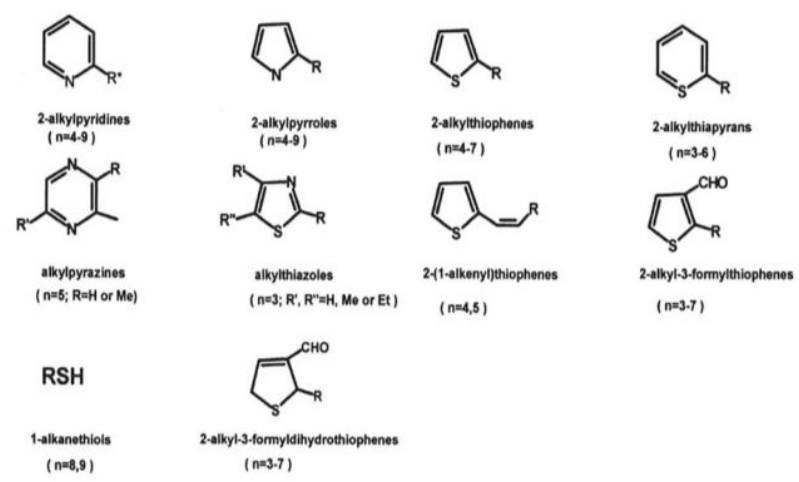

Figure 6. Volatile compounds of lipid-Maillard interaction (Melton, 1999).

lipid-Maillard interactions are given in Table 4 and 5 . Several thiazoles with $\mathrm{C}_{4}$ to $\mathrm{C}_{8} n$-alkyl substituents in the 2-position and some other alkylthiazoles with much longer 2-alkyl substituents $\left(\mathrm{C}_{13}\right.$ to $\left.\mathrm{C}_{15}\right)$ have been reported in fried chicken and heated chicken, respectively (Tang et al., 1983; Farmer and Mottram, 1994). Melton (1999) reported that 2octyl-4,5-dimethylthiazole found in chicken meat is also a product from interaction of Maillard reactions and lipids.

\section{Other compounds contributing to roasted, fried and boiled chicken flavour}

Heterocyclic compounds such as pyrazines, thiazoles and oxazoles are usually considered to be responsible for the roast flavours in foods including meat. Melton (1999) reported that a large number of heterocyclic compounds are associated with roasted, grilled, fried or pressure cooked meats, but not boiled meat, due to higher temperatures used in those cooking methods. Different alkyl pyrazines and two classes of bicyclic compounds, 6,7-dihydro-5(H)cyclopentapyrazines and pyrrolopyrazines, were found in meat volatiles (Mottram, 1998). It was noticed that both classes of compounds increased greatly with the increasing severity of heat treatment. However, Mottram (1991) reported that boiled meat contained higher levels of sulfurcontaining heterocyclic compounds such as thiophenes,

Table 4. Selected lipid-Maillard product in cooked meat (adapted from Melton, 1999)

\begin{tabular}{lcccc}
\hline Compound & Beef & Chicken Turkey & Lamb \\
\hline 1-Heptanethiol & $\mathrm{D}^{1}$ & - & - & - \\
2-Pentylpyridine & $\mathrm{D}, \mathrm{R}^{2}$ & $\mathrm{D}, \mathrm{R}$ & $\mathrm{R}$ & $\mathrm{R}$ \\
2-Buthylthiophene & $\mathrm{R}$ & $\mathrm{R}$ & - & - \\
2-Hexylthiophene & $\mathrm{R}$ & $\mathrm{D}$ & $\mathrm{R}$ & - \\
2-Pentylthiapyran & $\mathrm{D}$ & $\mathrm{ND}^{3}$ & - & - \\
2-Alkyl-3-formyldihydro-thiophenes & $\mathrm{ND}$ & $\mathrm{ND}$ & - & - \\
2-Propyl-3-formyldihydro-thiophene & $\mathrm{ND}$ & $\mathrm{D}$ & - & - \\
2-Butyl-3-formyldihydro-thiophene & $\mathrm{ND}$ & $\mathrm{D}$ & - & - \\
2-Hexyl-3-formyldihydro-thiophene & $\mathrm{D}$ & $\mathrm{D}$ & - & - \\
\hline
\end{tabular}

${ }^{1} \mathrm{D}=$ Detected. ${ }^{2} \mathrm{R}=$ Reported in literature. ${ }^{3} \mathrm{ND}=$ Not detected.
Table 5. Occurrence of some long-chain alkylthiazoles in meat (adapted from Melton, 1999)

\begin{tabular}{lccc}
\hline Thiazole & Beef heart & $\begin{array}{c}\text { Beef } \\
\text { Longissimus } \\
\text { dorsi }\end{array}$ & $\begin{array}{c}\text { Chicken } \\
\text { breast }\end{array}$ \\
\hline 5-Octyl-4-ethyl & $-{ }^{1}$ & $\operatorname{tr}^{2}$ & $+++^{5}$ \\
5-Nonyl-ethyl & $+^{3}$ & $++^{4}$ & +++ \\
5-Decyl-4-ethyl & - & $\operatorname{tr}$ & ++ \\
2-Tridecyl-4,5-dimethyl & + & $\operatorname{tr}$ & - \\
2-Tridecyl-4/5-ethyl & ++ & - & - \\
2-Tetradecyl-4,5-dimethyl & + & - & - \\
2-Pentadecyl & $\operatorname{tr}$ & $\operatorname{tr}$ & +++ \\
2-Pentadecyl-4-methyl & +++ & ++ & ++ \\
2-Pentadecyl-4/5-ethyl & +++ & ++ & ++ \\
\hline${ }^{1}$ Absent. ${ }^{2}$ Trace. ${ }^{3}$ Slight. ${ }^{4}$ Moderate. ${ }^{5}$ Abundant. &
\end{tabular}

trithiolanes, trithianes that have low odour thresholds with sulfurous, onion-like and, sometimes, meaty aromas (Fors, 1983). These compounds contributed to the overall flavour and aroma of boiled meat.

Thermal degradation of cysteine and glutathione results in two major volatile compounds of fried chicken. At frying temperature $\left(180^{\circ} \mathrm{C}\right)$, cysteine produced 3,5-dimethyl-1,2,4trithiolanes and 2,4,6-trimethylperhydro-1,3,5-dithiazines (thialdine) whereas only the former compound was produced by glutathione at the same condition. These volatiles were identified in cooked chicken as well (Shi and Ho, 1994). In addition to 3,5-dimethyl-1,2,4-trithiolanes, three other alkyl-substituted trithiolanes, 3,5-diisobutyl1,2,4-trithiolane, 3-methyl-5-butyl-1,2,4-trithiolane and 3methyl-5-pentyl-1,2,4-trithiolane, were identified in fried chicken flavour. The formation of latter 2 volatiles involves thermal and oxidative degradation of lipids, pentanal and hexanal (Shi and Ho, 1994). Possible mechanisms for the formation of dithiazines and 3,5-diisobutyl-1,2,4-trithiolane are given in Figure 7. According to Shi and Ho (1994), flavour of deep-fat-fried foods such as fried chicken is attributed to lipid-derived aldehyde, 2,4-decadienal. Being an oxidation product of 2,4-decadienal, trans-4,5-epoxytrans-2-decenal having a low odour threshold plays a key role in the flavour of fried chicken.

Heterocyclic compounds, mainly pyrazines, pyridines, pyrroles and thiazoles, found in fried and roasted chicken are listed in Table 6. Alkylpyrazines have a roasted, nut-like or toasted flavour notes and are present in the flavours of fried chicken and roasted chicken but not in chicken broth. This confirms that the generation of pyrazines requires high temperature and low moisture. Shi and Ho (1994) reported that fried chicken flavour was further intensified by 2-pentylpyridine (strong fatty and tallow-like odour), 2-isobutyl-3,5-diisopropylpyridine (roasted cocoa-like aroma), 2-pentyl-4-methyl-5-ethylthiazole (strong paprika pepper flavour), 2-heptyl-4,5-dimethylthiazole (strong spicy 
(a)

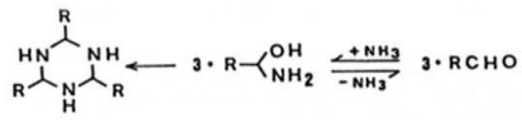<smiles>[C]#C</smiles>

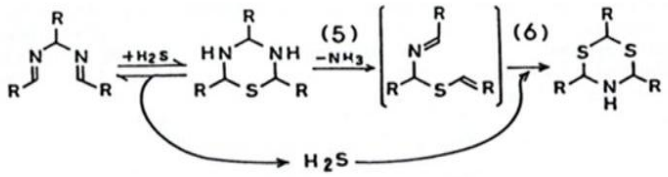

(b)

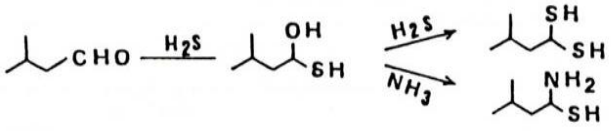

$$
\begin{aligned}
& ᄉ_{S H}^{S H}+{ }_{H S}^{H S} \lambda \frac{-H_{2} S}{(0)} \overbrace{S}^{S-S} \lambda
\end{aligned}
$$

Figure 7. Possible mechanisms for the formation of (a) dithiazines and (b) 3,5-diisobutyl-1,2,4-trithiolane (Shi and Ho, 1994).

flavour) and 2-octyl-4,5-dimethylthiazole (sweet fatty aroma).

\section{OFF-FLAVOURS OF CHICKEN MEAT}

Lipid oxidation has been considered as the primary cause of flavour deterioration and development of offflavour known as oxidized flavours or "warmed-over flavour (WOF)" in poultry meat (Lillard, 1987; Shi and Ho, 1994). Generally WOF is generated within $24 \mathrm{~h}$ of refrigerated storage in precooked poultry (Graf and Panter, 1991). WOF development is also related to rancid, and sulfur/rubber sensory notes and a parallel reduction in chicken "meaty" flavour can also be observed. A remarkable off-flavour problem in mechanically deboned chicken meat was reported by Shi and Ho (1994) and it was attributed to rancidity of fat. It was further stated by the same authors that haem pigments, being the catalyst of the above reaction, are largely responsible for the off-flavour formation. However, recent studies indicated that raw poultry meats are highly resistant to oxidative changes due to various antioxidants present in chicken meat (Min et al., 2010). Meanwhile, it has also been reported that increasing cooking temperature is associated with increased roasted, toasted, and bitter sensory notes (Perez-Alvarez et al., 2010). Studies conducted to determine the critical changes in odour compounds of boiled chicken during refrigerated storage and reheating proved that refrigerated storage and reheating of boiled chicken showing WOF due to loss of meaty, chicken-like and sweet odour notes, and the formation of green, cardboard-like, and metallic off-odours by the secondary by-products of lipid oxidation. These changes
Table 6. Heterocyclic compounds identified in fried and roasted chicken flavours (adapted from Shi and Ho, 1994)

\begin{tabular}{|c|c|c|c|}
\hline \multicolumn{2}{|l|}{ Compound } & \multirow{2}{*}{$\begin{array}{c}\text { Fried } \\
\text { Chicken }\end{array}$} & \multirow[t]{2}{*}{$\begin{array}{l}\text { Roasted } \\
\text { Chicker }\end{array}$} \\
\hline Pyrazines & Pyrazine & & \\
\hline & 2-Methylpyrazine & + & + \\
\hline & 2,3-Dimethylpyrazine & + & + \\
\hline & 2,5-Dimethylpyrazine & + & \\
\hline & 2,6-Dimethylpyrazine & + & + \\
\hline & Trimethylpyrazine & + & + \\
\hline & 2-Isopropylpyrazine & + & \\
\hline & 2-Methyl-3-ethylpyrazine & + & + \\
\hline & 2-Methyl-6(5)-ethylpyrazine & + & + \\
\hline & 2-Butylpyrazine & + & \\
\hline & 2,3-Dimethyl-5-ethylpyrazine & + & + \\
\hline & 2,5-Dimethyl-3-ethylpyrazine & + & \\
\hline & 2,6-Dimethyl-3-ethylpyrazine & & + \\
\hline & 2,6-Diethylpyrazine & + & + \\
\hline & 2-Methyl-5,6-diethylpyrazine & + & \\
\hline & 2-Methyl-3,5-diethylpyrazine & + & \\
\hline & 2-Methyl-3-butylpyrazine & + & \\
\hline & 2-Methyl-5-vinylpyrazine & + & \\
\hline & 2-Methyl-6-vinylpyrazine & + & \\
\hline & 2-Isopropenylpyrazine & + & \\
\hline & 6,7-Dihydro-5H-cyclopentapyrazine & + & \\
\hline & $\begin{array}{l}\text { 2-Methyl-6,7-dihydro-5H- } \\
\text { cyclopentapyrazine }\end{array}$ & + & \\
\hline \multirow[t]{9}{*}{ Pyridines } & Pyridine & + & + \\
\hline & 2-Methylpyridine & + & + \\
\hline & 3-Ethylpyridine & + & + \\
\hline & 4-Ethylpyridine & + & \\
\hline & 2-Methyl-5-ethylpyridine & + & + \\
\hline & 2-Ethyl-3-methylpyridine & + & \\
\hline & 2-Butylpyridine & + & \\
\hline & 2-Pentylpyridine & + & \\
\hline & 2-Isobutyl-3,5-dipropylpyridine & + & \\
\hline \multirow[t]{10}{*}{ Pyrroles } & Pyrrole & + & + \\
\hline & $N$-methylpyrrole & & + \\
\hline & 2-Methylpyrrole & + & \\
\hline & 2-Ethylpyrrole & & + \\
\hline & $N$-acetylpyrrole & & + \\
\hline & 2-Acetylpyrrole & + & \\
\hline & 2-Isobutylpyrrole & + & \\
\hline & $N$-isobutylpyrrole & + & \\
\hline & $N$-(2-butanoyl)pyrrole & + & \\
\hline & $N$-furfurylpyrrole & & + \\
\hline \multirow[t]{16}{*}{ Thiazoles } & Thiazole & + & + \\
\hline & 2-Methylthiazole & + & + \\
\hline & 2,4,5-Trimethylthiazole & + & \\
\hline & 2-Methyl-4-ethylthiazole & + & \\
\hline & 2-Methyl-5-ethylthiazole & & + \\
\hline & 2,4-Dimethyl-5-ethylthiazole & + & \\
\hline & 2-Isopropyl-4,5-dimethylthiazole & + & \\
\hline & 2,5-Dimethyl-4-butylthiazole & + & \\
\hline & 2-Isopropyl-4-ethyl-5-methylthiazole & + & \\
\hline & 2-Butyl-4,5-dimethylthiazole & + & \\
\hline & 2-Butyl-4-methyl-5-ethylthiazole & + & \\
\hline & 2-Pentyl-4,5-dimethylthiazole & + & \\
\hline & 2-Hexyl-4,5-dimethylthiazole & + & \\
\hline & 2-Heptyl-4,5-dimethylthiazole & + & \\
\hline & 2-Heptyl-4-ethyl-5-methylthiazole & + & \\
\hline & 2-Octyl-4,5-dimethylthiazole & + & \\
\hline
\end{tabular}

$+=$ Present 
were caused primarily by an increase in hexanal (sevenfold) and six fold decrease in both $(E, E)$-2,4-decadienal and 2furfurylthiol (Kerler and Grosch, 1997). Rhee et al. (2005) reported that "cardboard" flavour and "sour" flavour intensity increased with storage time for chicken breast, while "cooked chicken" intensity decreased and, "cardboard" intensity increased for chicken thigh. Results further illustrated relative storage effects on intensity of the species specific natural meat flavours and "cardboard" flavour, with d-3 and d-6 scores expressed relative to d-0 scores. However, chicken exhibited the slowest rate of decrease in species-specific natural flavour intensity and the slowest rate of increase in "cardboard" flavour intensity compare to pork and beef.

\section{FACTORS AFFECTING CHICKEN MEAT FLAVOUR}

Findings of researches conducted over years have shown that several pre- and post-mortem factors affect the flavour of chicken meat. Breed/strain of the chicken, diet of the bird, presence of free amino acids and nucleotides, irradiation, high pressure treatment, cooking, antioxidants, $\mathrm{pH}$, sex, and ageing are considered as the main determinants (Farmer, 1999; Jayasena et al., 2013). Different breeds/strains contain different levels of flavour precursors such as IMP leading to various types and concentrations of volatile compounds. Increased palatability of indigenous chicken compared to broilers is well documented by many authors. Superior flavour of Korean native/farm chicken, Hinai-jidori chicken (Japan), Wenchang and Xianju (China) to broilers has been reported (Tang et al., 2009; Jung et al., 2011; Kiyohara et al., 2011). Additionally, chicken results in more unsaturated volatile aldehydes as compared to beef or lamb because their muscle contains higher levels of polyunsaturated fatty acids in the triglycerides than later species (Calkins and Hodgen, 2007). These compounds contribute to the specific aromas of chicken (Noleau and Toulemonde, 1987; Mottram, 1991). This confirms the effect of lipids on the flavour of chicken primarily via the differences in fatty acid composition and the resulting carbonyls (Perez-Alvarez et al., 2010). Further, positive correlations between the flavour of chicken meat and the intramuscular contents of amino acids, including glutamic acid and nucleotides, such as IMP were demonstrated by Kurihara (1987), Rikimaru and Takahashi (2010) and Takahashi et al. (2012). Effect of sex on chicken meat flavour was demonstrated by many researchers, although the results were not consistent. Meat from male birds received higher scores for flavour as opposed to that from female birds (Ramaswamy and Richards, 1982; Farmer, 1999). However, it was also shown that the breast and leg meat of female birds were preferred to those of male birds. Many other researchers reported no significant relationship between the two parameters (Farmer, 1999).

In addition to these intramuscular compounds, the diet of the bird also plays a vital role towards the flavour of chicken meat (Fanatico et al., 2007; Perez-Alvarez et al., 2010). Diet can either positively or negatively influence the flavour of chicken meat. Corn-fed chicken and arachidonic acid enriched diet fed chicken have produced tastier meat (Lyon et al., 2004; Kiyohara et al., 2011; Takahashi et al., 2012) while diets supplemented with fish meal have negatively affected the flavour of chicken meat (Poste, 1990). Processing steps such as aging, cooking, irradiation and high pressure treatment also affect the flavour of chicken meat. Post-mortem aging results in many chemical flavour compounds including sugars, organic acids, peptides, free amino acids (Yano et al., 1995; Spanier et al., 2004) and thereby leads to increased flavour. Cooking plays a vital role in flavour development and it affects the acceptability and volatile flavour components of poultry meat (Sanudo et al., 2000). Cooking methods such as roasting, grilling, frying, and pressure cooking generates many pyrazines, pyridines, pyrroles and thiazoles compared to boiling of chicken meat (Shi and Ho, 1994). Irradiation affects flavour and aroma of chicken meat primarily through the production of free radicals. Aldehydes (hexanal, pentanal, heptanal, octanal, and nonanal) and sulfur volatiles mainly dimethyl trisulfide generated during irradiation result in the associated off-odour (Patterson and Stevenson, 1995; Perez-Alvarez et al., 2010). However, very little negative effect was expressed by electron beam irradiation on the flavour of preheated chicken breast meat (Rababah, 2006). Effect of high pressure treatment on flavour of meat including chicken meat had been variable over the years. Hayman et al. (2004) showed that the sensory quality of various meat products was not affected by high pressure treatment. However, exposure of chicken meat to a pressure of $300 \mathrm{MPa}$ lead to a better flavour and taste as opposed to a $450 \mathrm{MPa}$ treatment (Kruk et al., 2011). According to Cheah and Ledward (1996), pressure treatments at around $300 \mathrm{MPa}$ at room temperature initiated the changes which eventually lead to catalysis of lipid oxidation in pressure processed meat.

\section{CONCLUSION}

The Maillard reaction, thermal degradation of lipids and Maillard-lipid interactions, are the main pathways by which a large number of flavour and aroma compounds responsible for chicken meat flavour are formed during cooking. Volatile compounds generated from the Maillard reaction and lipid oxidation including 2-methyl-3-furanthiol, 2-furfurylthiol, methionol, 2,4,5-trimethylthiazole, nonanol, 2-trans-nonenal, 2-formyl-5-methylthiophene, p-cresol, 2- 
trans-4-trans-nonadienal, 2-trans-4-trans-decadienal, 2undecenal, $\beta$-ionone, $\gamma$-decalactone and $\gamma$-dodecalactone are obviously the major sources of chicken flavour. However 2methyl-3-furanthiol that is produced from the reaction between ribose and cysteine or cystine, and from degradation of thiamin is considered as the most important compound in chicken flavour.

A large number of heterocyclic compounds are formed during roasting, grilling, frying or pressure cooking of chicken meat due to higher temperature and low moisture conditions used in those cooking methods. These compounds are absent in boiled meat. Major volatile compounds responsible for fried chicken are 3,5-dimethyl1,2,4-trithiolanes, 2,4,6-trimethylperhydro-1,3,5-dithiazines, 3,5-diisobutyl-1,2,4-trithiolane, 3-methyl-5-butyl-1,2,4trithiolane, 3-methyl-5-pentyl-1,2,4-trithiolane, 2,4decadienal and trans-4,5-epoxy-trans-2-decenal. Alkylpyrazines were reported in the flavours of fried chicken and roasted chicken but not in chicken broth. Flavour of chicken meat is affected by breed/strain of chicken, diet of bird, presence of free amino acids and nucleotides, irradiation, high pressure treatment, cooking, antioxidants and ageing.

\section{ACKNOWLEDGEMENT}

This work was carried out with the support of "Cooperative Research Program for Agriculture Sciecne \& Technology Development (Project No. PJ90701104)” Rural Development Administration, Korea.

\section{REFERENCES}

Aliani, M. and L. J. Farmer. 2005. Precursors of chicken flavour II: Identification of key flavour precursors using sensory methods. J. Agric. Food Chem. 53:6455-6462.

Brunton, N. P., D. A. Cronin and F. J. Monahan. 2002. Volatile components associated with freshly cooked and oxidized offflavours in turkey breast meat. Flavour Fragr. J. 17:327-334.

Calkins, C. R. and J. M. Hodgen. 2007. A fresh look at meat flavour. Meat Sci. 77:63-80.

Cheah, P. B. and D. A. Ledward. 1996. High pressure effects on lipid oxidation in minced pork. Meat Sci. 43:123-134.

Choe, J. H., K. Nam, S. Jung, B. Kim, H. J. Yun and C. Jo. 2010. Differences in the quality characteristics between commercial Korean native chickens and broilers. Korean J. Food Sci. Anim. Resour. 30:13-19.

Fanatico, A. C., P. B. Pillai, J. L. Emmert, E. E. Gbur, J. F. Meullenet and C. M. Owens. 2007. Sensory attributes of slowand fast-growing chicken genotypes raised indoors or with outdoor access. Poult. Sci. 86:2441-2449.

Farmer, L. J. 1999. Poultry meat flavour. In: Poultry Meat Science: Poultry Science Symposium Series Vol. 25 (Ed. R. I. Richardson and G. C. Mead). CABI Publishing, Oxon. pp. 127-158.
Farmer, L. J. and D. S. Mottram. 1994. Lipid-Maillard interactions in the formation of volatile aroma compounds. In: Trends in Flavour Research (Ed. H. Maarse and D. G. vander Heij). Elsevier, Amsterdam. pp. 313-326.

Fors, S. 1983. Sensory properties of volatile Maillard reaction products and related compounds. In: The Maillard Reaction in Foods and Nutrition (Ed. G. R. Waller and M. S. Feather). American Chemical Society, Washington. pp. 185-286.

Gasser, U. and W. Grosch. 1990. Primary odorants of chicken broth: A comparative study with meat broths from cow and ox. Z. Lebensm. Unters. Forsch. 190:3-8.

Graf, E. and S. S. Panter. 1991. Inhibition of warmed-over flavour development by polyvalent cations. J. Food Sci. 56:1055-1058.

Hayman, M. M., I. Baxter, P. J. O'Riordan and C. M. Stewart. 2004. Effects of high pressure processing on the safety, quality, and shelf life of ready-to-eat meats. J. Food Prot. 67:17091718.

Ho, C. T., Y. C. Oh and M. Bae-Lee. 1994. The flavour of pork. In: Flavour of Meat and Meat Products (Ed. F. Shahidi). Blackie Academic and Professional, London. pp. 38-51.

Jaturasitha, S., T. Srikanchai, M. Kreuzer and M. Wicke. 2008. Difference in carcass and meat characteristics between chicken indigenous to northern Thailand (Black-boned and Thai native) and imported extensive breeds (Bresse and Rhode Island Red). Poult. Sci. 87:160-169.

Jayasena, D. D., D. U. Ahn, K. C. Nam and C. Jo. 2013. Factors affecting cooked chicken meat flavor: A review. Worlds Poult. Sci. J. (In press).

Joo, S. T. and G. D. Kim. 2011. Meat quality traits and control technologies. In: Control of Meat Quality (Ed. S. T. Joo). Research Signpost, Kerala: pp. 1-20.

Jung, Y., H. J. Jeon, S. Jung, J. H. Choe, J. H. Lee, K. N. Heo, B. S. Kang and C. Jo. 2011. Comparison of quality traits of thigh meat from Korean native chickens and broilers. Korean J. Food Sci. Anim. Resour. 31:684-692.

Kavitha, S. and V. K. Modi. 2007. Effect of water activity and temperature on degradation of 5 '-inosine monophosphate in a meat model system. LWT-Food Sci. Technol. 40:1280-1286.

Kerler, J. and W. Grosch. 1997. Character impact odourants of boiled chicken: changes during refrigerated storage and reheating. Eur. Food Res. Technol. 205:232-238.

Kiyohara, R., S. Yamaguchi, K. Rikimaru and H. Takahashi. 2011. Supplemental arachidonic acid-enriched oil improves the taste of thigh meat of Hinai-jidori chickens. Poult. Sci. 90:18171822.

Kruk, Z. A., H. Yun, D. L. Rutley, E. J. Lee, Y. J. Kim and C. Jo. 2011. The effect of high pressure on microbial population, meat quality and sensory characteristics of chicken breast fillet. Food Control 22:6-12.

Kurihara, K. 1987. Recent progress in the taste receptor. In: Umami: A Basic Taste (Ed. Y. Kawamura and M. R. Kare). Marcel Dekker, New York. pp. 3-39.

Lillard, D. A. 1987. Oxidative deterioration in meat, poultry, and fish. In: Warmed-Over Flavour of Meat (Ed. A. J. St. Angelo and M. E. Bailey). Academic Press, Orlando. pp. 41-67.

Liu, X. D., D. D. Jayasena, Y. Jung, S. Jung, B. S. Kang, K. N. Heo, J. H. Lee and C. Jo. 2012. Differential proteome analysis of breast and thigh muscles between Korean native chickens and commercial broilers. Asian Australas. J. Anim. Sci. 
25:895-902.

Lyon, B. G., D. P. Smith, C. E. Lyon and E. M. Savage. 2004. Effects of diet and feed withdrawal on the sensory descriptive and instrumental profiles of broiler breast fillets. Poult. Sci. 83:275-281.

MacLeod, G. 1994. The flavour of beef. In: Flavour of Meat and Meat Products (Ed. F. Shahidi). Blackie Academic and Professional, Glasgow. pp. 4-37.

Maga, J. A. 1983. Flavour potentiator. Crit. Rev. Food Sci. Nutr. 18:231-312.

Meinert, L., A. Schäfer, C. Bjergegaard, M. D. Aaslyng and W. L. Bredie. 2009. Comparison of glucose, glucose 6-phosphate, ribose, and mannose as flavour precursors in pork; the effect of monosaccharide addition on flavour generation. Meat Sci. 81:419-425.

Melton, S. L. 1999. Current status of meat flavour. In: Quality Attributes of Muscle Foods (Ed. Y. L. Xiong, C. T. Ho and F. Shahidi). Kluwer Academic/ Plenum Publishers, New York. pp. 115-130.

Min, B., J. C. Cordray and D. U. Ahn. 2010. Effect of $\mathrm{NaCl}$, myoglobin, $\mathrm{Fe}(\mathrm{II})$, and $\mathrm{Fe}(\mathrm{III})$ on lipid oxidation of raw and cooked chicken breast and beef loin. J. Agric. Food Chem. 58:600-605.

Mottram, D. S. 1991. Meat. In: Volatile Compounds in Foods and Beverages (Ed. H. Maarse). Marcel Dekker, New York. pp. 107-177.

Mottram, D. S. 1994a. Flavour compounds formed during the Maillard reaction. In Thermally Generated Flavours. Maillard, Microwave, and Extrusion Processes (Ed. T. H. Parliament, M. J. Morello and R. J. McGorrin). American Chemical Society, Washington. pp. 104-126.

Mottram, D. S. 1994b. Some aspects of the chemistry of meat flavour. In: The Flavour of Meat and Meat Products (Ed. F. Shahidi). Chapman and Hall, London. pp. 210-230.

Mottram, D. S. 1998. Flavour formation in meat and meat products: a review. Food Chem. 62:415-424.

Mottram, D. S. and R. A. Edwards. 1983. The role of triglycerides and phospholipids in the aroma of cooked beef. J. Sci. Food Agric. 34:517-522.

Mottram, D. S. and M. S. Madruga. 1994. Important sulfur containing aroma volatiles in meat. In: Sulfur Compounds in Foods (Ed. C. J. Mussinan and M. E. Keelan). American Chemical Society, Washington. pp. 180-187.

Noleau, I. and B. Toulemonde. 1987. Volatile components of roasted chicken fat. LWT-Food Sci. Technol. 20:37-41.

Patterson, R. L. and M. H. Stevenson. 1995. Irradiation-induced off-odor in chicken and its possible control. Br. Poult. Sci. 36:425-441.

Perez-Alvarez, J. A., E. Sendra-Nadal, E. J. Sanchez-Zapata and M. Viuda-Martos. 2010. Poultry flavour: General aspects and applications. In: Handbook of Poultry Science and Technology Volume 2: Secondary Processing (Ed. I. Guerrero-Legarreta and Y. H. Hui). John Wiley and Sons Inc, New Jersey. pp. 339357.

Poste, L. M. 1990. A sensory perspective of effect of feeds on flavor in meats: Poultry meats. J. Anim. Sci. 68:4414-4420.

Rababah, T., N. S. Hettiarachchy, R. Horax, M. J. Cho, B. Davis and J. Dickson. 2006. Thiobarbituric acid reactive substances and volatile compounds in chicken breast meat infused with plant extracts and subjected to electron beam irradiation. Poult. Sci. 85:1107-1113.

Ramaswamy, H. S. and J. F. Richards. 1982. Flavour of poultry meat- a review. Can. Inst. Food Sci. Technol. J. 15:7-18.

Rhee, K. S., L. M. Anderson and A. R. Sams. 2005. Comparison of flavour changes in cooked-refrigerated beef, pork and chicken meat patties. Meat Sci. 71:392-396.

Rikimaru, K. and H. Takahashi. 2010. Evaluation of the meat from Hinai-jidori chickens and broilers:Analysis of general biochemical components, free amino acids, inosine 5'monophosphate, and fatty acids. J. Appl. Poult. Res. 19:327333.

Sanudo, C., M. E. Enser, M. M. Campo, G. R. Nute, G. Maria, I. Sierra and J. D. Wood. 2000. Fatty acid composition and sensory characteristics of lamb carcasses from Britain and Spain. Meat Sci. 54:339-346.

Sasaki, K., M. Motoyama and M. Mitsumoto. 2007. Changes in the amounts of water-soluble umami-related substances in porcine longissimus and biceps femoris muscles during moist heat cooking. Meat Sci. 77:167-172.

Shahidi, F. 1989. Flavour of cooked meats. In: Flavour Chemistry: Trends and Developments (Ed. R. Teranishi, R. G. Buttery and F. Shahidi). American Chemical Society, Washington. pp. 188201.

Shahidi, F. 1994. Flavour of meat and meat products-an overview. In: Flavour of Meat and Meat Products (Ed. F. Shahidi). Blackie Academic and Professional, Glasgow. pp. 1-3.

Shahidi, F. 2002. Lipid derived flavours in meat products. In: Meat Processing: Improving Quality (Ed. J. Kerry, J. Kerry and D. Ledward). Woodhead Publishing Ltd, Cambridge. pp. 105-121.

Shi, H. and C. T. Ho. 1994. The flavour of poultry meat. In: Flavour of Meat and Meat Products (Ed. F. Shahidi). Blackie Academic and Professional, Glasgow. pp. 52-69.

Sitz, B. M., C. R. Calkins, D. M. Feuz, W. J. Umberger and K. M. Eskridge. 2005. Consumer sensory acceptance and value of domestic, Canadian, and Australian grass-fed beef steaks. J. Anim. Sci. 83:2863-2868.

Spanier A. M., M. Flores, F. Toldrá, M. C. Aristoy, K. L. Bett, P. Bystricky and J. M. Bland. 2004. Meat flavor: contribution of proteins and peptides to the flavor of beef. Adv. Exp. Med. Biol. 542:33-49.

Spanier, A. M., M. Flores, K. W. Mcmillin and T. D. Bidner. 1997. The effect of postmortem aging on meat flavour quality. Correlation of treatment, sensory, instrumental, and chemical descriptors. Food Chem. 59:531-538.

Takahashi, H., K. Rikimaru, R. Kiyohara and S. Yamaguchi. 2012. Effect of arachidonic acid-enriched oil diet supplementation on the taste of broiler meat. Asian Australas. J. Anim. Sci. 25:845-851.

Tang, H., Y. Z. Gong, C. X. Wu, J. Jiang, Y. Wang and K. Li. 2009. Variation of meat quality traits among five genotypes of chicken. Poult. Sci. 88:2212-2218.

Tang, J., Q. Z. Jin, G. H. Shen, C. T. Ho and S. S. Chang. 1983. Isolation and identification of volatile compounds from fried chicken. J. Agric. Food Chem. 31:1287-1292.

Varavinit, S., S. Shobsngob, M. Bhidyachakorawat and M. Suphantharika. 2000. Production of meat-like flavour. Science Asia. 26:219-224.

Wasserman, A. E. 1972. Thermally produced flavour components 
in the aroma of meat and poultry. J. Agric. Food Chem. Yamaguchi, S. 1991. Roles and efficacy of sensory evaluation in 20:737-741. studies of taste. J. Japan Soc. Food Sci. Technol. 38:972-978.

Wattanachant, S., S. Benjakul and D. A. Ledward. 2004. Yano, T., N. Kataho, M. Watanabe, T. Nakamura and Y. Asano. Composition, color, and texture of Thai indigenous and broiler chicken muscles. Poult. Sci. 83:123-128.

Whitfield, F. B. 1992. Volatiles from interactions of Maillard reactions and lipids. Crit. Rev. Food Sci. Nutr. 31:1-58. 1995. Evaluation of beef aging by determination of hypoxanthine and xanthine contents: application of a xanthine sensor. Food Chem. 52:439-445. 